\title{
EXPERIÊNCIAS FORMATIVAS ACERCA DO ESTÁGIO CURRICULAR SUPERVISIONADO NA EDUCAÇÃO INFANTIL EM TEMPOS DE PANDEMIA ${ }^{1}$
}

\author{
FORMATIVE EXPERIENCES ABOUT THE OBSERVED CURRICULAR \\ INTERNSHIPS IN EARLY CHILDHOOD EDUCATION IN PANDEMIC TIMES
}

\author{
Sandra Beatriz de Andrade Cardozo 2 , Juliana Helena Treichel ${ }^{3}$ e \\ Fernanda Figueira Marquezan ${ }^{4}$
}

\section{RESUMO}

O artigo aborda os estágios curriculares supervisionados na formação de professores de Educação Infantil. Desse modo, objetiva descrever e analisar experiências formativas produzidas no Estágio Curricular Supervisionado - Docência na Educação Infantil, Curso de Pedagogia da Universidade Franciscana (UFN), Santa Maria/RS. As atividades didático-pedagógicas promovidas durante o estágio foram realizadas em tempos de isolamento social em virtude da pandemia da COVID-19. O campo de estágio foi a E.M.E.F. Maria de Lourdes Ramos Castro em turma de pré-escola. A metodologia pautou-se na abordagem qualitativa e no método autobiográfico. Ao projetar uma proposta de estágio via ensino remoto, julgou-se, oportuno, para o desenvolvimento das atividades pedagógicas, apoiar-se na Base Nacional Comum Curricular - BNCC (BRASIL, 2017). A experiência demonstrou os desafios impostos aos profissionais da pedagogia, nesse contexto de pandemia, de modo especial às professoras de Educação Infantil, uma vez que o contato por meio virtual com as crianças é inédito em contexto brasileiro. Por fim, a proposição de estágio curricular, na Educação Infantil, na modalidade remota, configurou-se como uma experiência formativa em que as estagiárias mobilizaram a produção de conhecimentos e de aprendizagens necessários à docência, em uma perspectiva reflexiva dos enfrentamentos de como ensinar e de que maneira aprender em tempos de pandemia.

Palavras-chave: Pré-escola; Ensino remoto; COVID-19.

\section{ABSTRACT}

The article deals with supervised curricular internships in the training of Early Childhood Education teachers. Thus, it aims at describing and analyzing the formative experiences from trainees in their Observed Curricular Internships - Teaching in Early Childhood Education, at the Pedagogy Course from the Franciscan University (UFN), Santa Maria/RS. The didactic-pedagogical activities promoted during internships were done during the social distancing time due to the COVID-19 Pandemics. The internships field was the pre-schooling group from the school EMEF Maria de Lourdes Ramos Castro. The methodology was based on the qualitative approach and the autobiographical method. When projecting the purpose of internships through remote learning, it was considered relevant, for the development of pedagogical activities, the support of the Commom Curricular National Base - BNCC (BRASIL, 2017). The experience showed the challenges demanded from the

\footnotetext{
${ }^{1}$ Trabalho resultante de práticas de Estágio Curricular Supervisionado - Docência na Educação Infantil, no Curso de Pedagogia da Universidade Franciscana (UFN).

${ }^{2}$ Acadêmica do Curso de Pedagogia - Universidade Franciscana. Mestre em Geografia. Professora de Geografia da Rede Privada de Santa Maria/RS.

${ }^{3}$ Acadêmica do Curso de Pedagogia - Universidade Franciscana.

${ }^{4}$ Orientadora, Professora dos Cursos de Mestrado em Ensino de Humanidades e Linguagens (MEHL) e de Pedagogia da Universidade Franciscana (UFN). E-mail: marquezanfernanda@gmail.com
} 
Pedagogy professionals, in this pandemic context, especially to the teachers of children education, once the online contact with kids is new in the Brazilian context. To sum, the proposal of remote curricular internships in Early Childhood Education has configures as a formative experience in which the trainees mobilized the production of necessary teaching knowledge, in a reflexive perspective of the challenges on how teaching and learning occurs in pandemic times.

Keywords: pre-school; remote teaching; COVID-19.

\section{INTRODUÇÃO}

O artigo objetiva descrever e analisar as experiências formativas produzidas por estagiárias durante Estágio Curricular Supervisionado IV - Docência na Educação Infantil. O referido estágio integra a matriz curricular do Curso de Pedagogia da Universidade Franciscana (UFN) e tem, por finalidade, realizar ações educativas inerentes à docência na Educação Infantil. As atividades didático-pedagógicas promovidas, durante o estágio, foram realizadas em tempos de distanciamento social em virtude da pandemia da COVID-19.

A COVID-19 é uma doença causada pelo coronavírus, denominado SARS-CoV-2, que apresenta um espectro clínico variando de infecções assintomáticas a quadros graves. De acordo com a Organização Mundial de Saúde (OMS, 2020), a maioria (cerca de 80\%) dos pacientes com COVID-19 podem ser assintomáticos ou oligossintomáticos (poucos sintomas), e aproximadamente $20 \%$ dos casos detectados requer atendimento hospitalar por apresentarem dificuldade respiratória, dos quais aproximadamente 5\% podem necessitar de suporte ventilatório. Diante da propagação vertiginosa da COVID-19, tornaram-se necessárias medidas críticas, por parte dos governantes de todos os países, inclusive do Brasil e de seus respectivos estados e municípios, com desafios impostos ao sistema de saúde, bem como ao sistema de educação, áreas afetadas diretamente pela pandemia.

Desse modo, a suspensão das aulas presenciais e o fechamento das escolas foram algumas medidas adotadas pelo governo brasileiro, repercutindo nas escolas da Rede Municipal de Educação (RME) de Santa Maria/RS, com vistas a proteger as crianças e os jovens e, assim, reduzir as chances de que eles se tornassem vetores do vírus para suas famílias e comunidades, sobretudo para os idosos e demais grupos de risco. Nesse sentido, foi promulgado, no dia 16 de março de 2020, o Decreto Executivo No 53 (SANTA MARIA, 2020), apoiado no Decreto Estadual No 55.154, de 12 de março de 2020 (RIO GRANDE DO SUL, 2020), em que se declarou a suspensão das atividades e das aulas da Rede Municipal de Santa Maria.

Além da suspensão das atividades educativas relativas à Educação Básica, as atividades da Educação Superior também foram suspensas por meio da Portaria $\mathrm{N}^{\mathrm{o}} 343$, de 17 de março de 2020, do Ministério da Educação (BRASIL, 2020). Tais medidas, em âmbito nacional e municipal, impactaram as atividades universitárias da Universidade Franciscana (UFN). Isso exigiu da gestão institucional e de docentes repensarem e recriarem as práticas docentes e as ações de ensino, pesquisa e extensão 
da Instituição, de modo especial, as práticas profissionais, como as dos Estágios Curriculares Supervisionados nos cursos de licenciatura.

Em vista disso, a coordenação do Curso de Pedagogia, juntamente com a coordenação dos Estágios Curriculares do curso, afirmou uma parceria de estágio, na Educação Infantil, na modalidade de ensino remoto com a E.M.E.F. Fundamental Maria de Lourdes Ramos Castro. A proposta de estágio apoiou-se no entendimento de que o estágio é um espaço formativo que possibilita, aos futuros professores, compreender o sentido da profissão, como ser professor e o que é ser professor na sociedade contemporânea.

Ao se proceder desse modo, entende-se que futuro professor encontra novas formas de entender a profissão, ou seja, adquire uma maior conscientização pessoal e profissional sobre o que é e como ser professor, construindo e fortalecendo sua identidade (MARQUEZAN; FLEIG, 2007). Nesse sentido, na atual conjuntura social, considera-se relevantes as estagiárias - professoras em formação, vivenciarem como reinventar e [res]significar a profissão de ser professor, em tempos de pandemia, com professoras mais experientes (professoras das turmas de Educação Infantil).

Dessa maneira, a partir da suspensão das aulas presenciais devido à pandemia da COVID-19, a modalidade remota foi a alternativa de ensino empregada, pela RME, com o objetivo de manter o vínculo das crianças com a escola, bem como com o intuito de promover ações educativas e pedagógicas com o propósito de permitir o desenvolvimento e a aprendizagem das crianças, haja vista que os alunos e alunas não poderiam ficar desassistidos nessa época de isolamento social, e garantir, assim, uma proximidade das crianças com suas professoras e o ambiente escolar. Nessa perspectiva, o desafio que o contexto propôs, às estagiárias e às professoras, foi o de como propor atividades pedagógicas que mantivessem o vínculo com as crianças e com as famílias/responsáveis, principalmente diante de limitações referentes ao acesso à internet, a computadores e a celulares, ferramentas essenciais para comunicação e realização das atividades.

A E.M.E.F. Maria de Lourdes Ramos Castro está localizada no Loteamento Leonel Brizola, na Vila Maringá (Santa Maria). Inaugurada pela Prefeitura Municipal em 2016, a instituição de ensino oferece Ensino Infantil e Ensino aos Anos Iniciais e Finais do Ensino Fundamental à comunidade do entorno da Vila. O estágio ocorreu na turma de Educação Infantil Pré A, constituída de 27 (vinte e sete) crianças. Dessas, 13 (treze) são meninos e 14 (catorze) são meninas. A maioria das crianças frequentou a Educação Infantil na turma do maternal, em 2019, na Instituição. Contudo, 07 (sete) crianças vieram de outras instituições recentemente, e algumas, ainda, estão frequentando a Escola pela primeira vez.

\section{METODOLOGIA}

Metodologicamente, o estudo caracteriza-se de abordagem qualitativa de natureza autobiográfica. Com esse tipo de abordagem, segundo Minayo (2003), trabalha-se com fenômenos que não podem ser 
quantificados, pois dizem respeito a motivos, a aspirações, a crenças e a atitudes. Por meio dela, respeitam-se as singularidades, busca-se compreender as relações vividas e que envolvem a sociedade.

O método autobiográfico tem sido entendido como estratégia de investigação qualitativa responsável por apresentar narrativas das histórias de vida de grupos humanos, sua leitura de mundo, suas afetividades, sentimentos, suas percepções e suas interações com o contexto sociocultural do qual as pessoas fazem parte (SANTOS; ESTEVAM; MARTINS, 2018).

Nessa linha de pensamento, a autobiografia, aliada à abordagem qualitativa, possibilita aprofundar a compreensão dos processos de formação, revelando-se como um "[...] instrumento de investigação, mas também e, sobretudo, como um instrumento de formação" (NÓVOA; FINGER, 2010). Nessa direção, o método autobiográfico tem, como objeto de estudo, o ser humano, em diferentes contextos e situações, quer narrando fatos de sua vida, quer refletindo sobre seu processo de autoformação. A pessoa, ao narrar, narra-se e, ao fazê-lo, ressignifica experiências, vivências, aprendizagens, dando-lhes novo significado.

Diante de tais concepções, justifica-se a escolha do método autobiográfico, uma vez que o estudo trata das experiências formativas de futuras pedagogas, produzidas durante o Estágio Curricular Supervisionado na Educação Infantil do curso de Pedagogia. Assim, as estagiárias, ao narrarem suas experiências, produziram novos significados por meio da reflexão acerca da formação de professores e da autoformação, na tentativa de compreender o processo de constituir-se professor e, de modo especial, neste estudo, a constituição do ser professora de Educação Infantil em tempos de pandemia.

\section{A DOCÊNCIA NA EDUCAÇÃO INFANTIL EM TEMPOS DE PANDEMIA}

Ao elaborar e ao implementar a proposta de estágio curricular via ensino remoto, diante do cenário de isolamento social, causada pela pandemia da COVID-19, a temática Cuidar de Si e da Família tornou-se imperativo, a fim de assinalar que o distanciamento proporcionou maior contato das crianças com as famílias/responsáveis. Nesse contexto, a quantidade e a qualidade do apoio dado à criança, para manter seus estudos e seu vínculo com a escola, varia conforme o contexto familiar. Ao mesmo tempo, a suspensão das aulas presenciais não pode significar interrupção do processo de aprendizagem, principalmente no caso de crianças com alta vulnerabilidade.

Em decorrência de tudo isso, julgou-se oportuno, para o desenvolvimento das atividades pedagógicas, apoiar-se na Base Nacional Comum Curricular (BNCC) (BRASIL, 2017), como documento orientador do planejamento curricular escolar, aliada à proposta pedagógica da Instituição. Assim, definiu-se explorar, como eixos norteadores, os seguintes Campos de Experiência: $\mathbf{O}$ eu, o outro e o nós e Corpo, gestos e movimentos. 
O Campo - O eu, o outro e o nós considera que é na interação com os pares e com adultos que as crianças começam a constituir um modo próprio de agir, sentir e pensar, de modo a descobrir que existem outros modos de vida e pessoas diferentes, com outros pontos de vista. Conforme vivem suas primeiras experiências sociais (na família, na instituição escolar, na coletividade), constroem percepções e questionamentos sobre si e sobre os outros, diferenciando-se e, simultaneamente, identificando-se como seres individuais e sociais (BRASIL, 2017).

Já o Campo - Corpo, gestos e movimentos esclarece que, com o corpo, por meio dos sentidos, gestos, movimentos impulsivos ou intencionais, coordenados ou espontâneos, as crianças, desde cedo, exploram o mundo, o espaço e os objetos do seu entorno. Ainda, elas estabelecem relações, expressam-se, brincam e produzem conhecimentos sobre si, a respeito do outro, acerca do universo social e cultural, tornando-se, progressivamente, conscientes dessa corporeidade. Por meio das diferentes linguagens, como a música e as brincadeiras de faz de conta, elas se comunicam e se expressam, no entrelaçamento entre corpo, emoção e linguagem. As crianças conhecem e reconhecem as sensações e as funções de seus corpos e, com seus gestos e movimentos, identificam suas potencialidades e seus limites, desenvolvendo, ao mesmo tempo, a consciência sobre o que é seguro e o que pode ser um risco à sua integridade física. Os campos selecionados para o desenvolvimento das atividades remotas se encontram próximos ao cotidiano e à realidade das crianças nesse momento vivido (BRASIL, 2017).

Logo, ao considerar os Campos de Experiência e os direitos de aprendizagem e desenvolvimento anunciados pela BNCC, para as crianças pequenas, com faixa etária de 04 a 05 anos de idade (faixa etária da turma de crianças), julgou-se imprescindível oportunizar o brincar cotidianamente de diversas formas, em diferentes espaços e tempos, com diferentes parceiros (criança-criança e criança-adultos), ampliando e diversificando seu acesso a produções culturais, seus conhecimentos, sua imaginação, sua criatividade, suas experiências emocionais, corporais, sensoriais, expressivas, cognitivas e relacionais.

Além disso, nesse período, entendeu-se que seria essencial explorar movimentos, gestos, sons, formas, texturas, cores, palavras, emoções, transformações, relacionamentos, histórias, objetos, elementos da natureza, na escola e fora dela, ampliando os saberes das crianças sobre a cultura, em suas diversas modalidades, a saber: as artes, a escrita, a ciência e a tecnologia. Nessa perspectiva, compreende-se que as atividades promovidas pela modalidade remota são possibilidades de práticas educativas em que os familiares podem colaborar e compartilhar com as crianças na produção e na construção das atividades mediadas pelas tecnologias digitais.

Diante da proposta de estágio, nos meses de maio a junho de 2020, foram realizadas 03 (três) atividades pedagógicas com as crianças do Pré A. As atividades eram divulgadas em grupo de WhatsApp composto pelos pais/responsáveis das crianças, pela professora regente da turma e 
pelas estagiárias. Em função da pandemia da Covid-19, os pais foram sensibilizados para se tornarem mediadores do processo de aprendizagem das crianças, e quaisquer questionamentos poderiam ser encaminhados às estagiárias (via grupo no WhatApps), a fim de que pudessem dar apoio às dificuldades encontradas na execução das atividades. A partir disso, as estagiárias entenderam que “[...] pais não são educadores, mas sim mediadores temporários, e ideia de que é preciso dar conta de tudo pode levar ao estresse tóxico para adultos e pequenos" (PINHEIRO, 2019).

Abaixo, são descritas as atividades solicitadas aos alunos e seus familiares, bem como são tecidas algumas reflexões acerca da recepção, do engajamento e da contribuição das atividades ao processo ensino e de aprendizagem das crianças.

Quadro 1 - Atividade 01 - Circuito de atividades

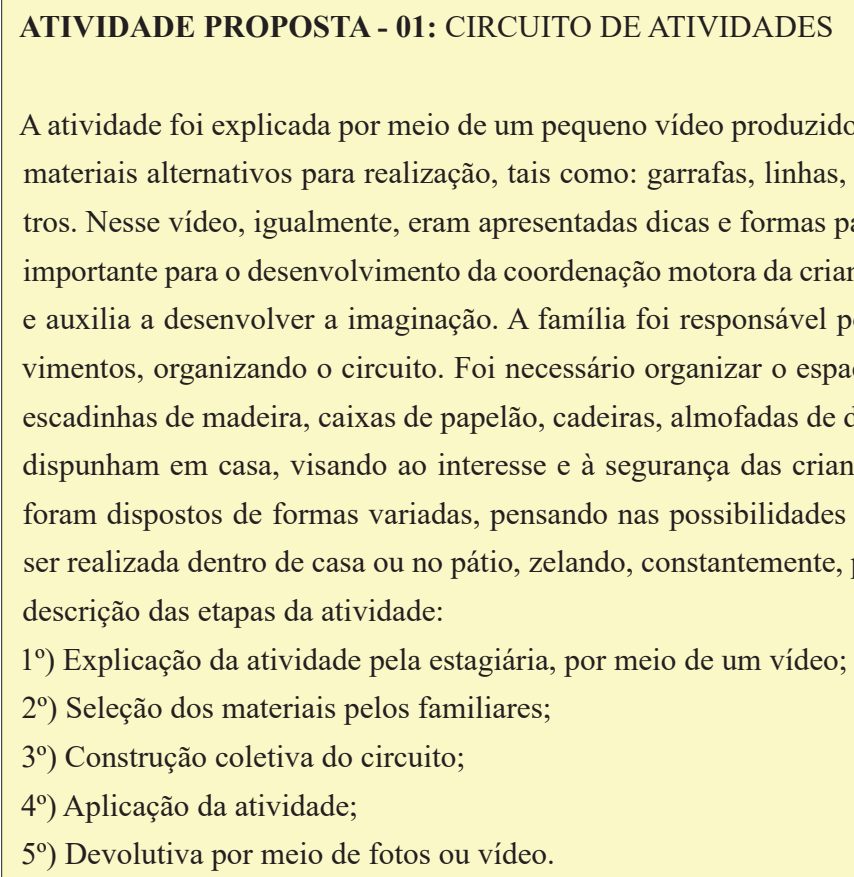
descrição das etapas da atividade:

$1^{\circ}$ ) Explicação da atividade pela estagiária, por meio de um vídeo;

$2^{\circ}$ ) Seleção dos materiais pelos familiares;

$3^{\circ}$ ) Construção coletiva do circuito;

$4^{\circ}$ ) Aplicação da atividade;

$5^{\circ}$ ) Devolutiva por meio de fotos ou vídeo. materiais alternativos para realização, tais como: garrafas, linhas, fitas, cordas, cabos de vassoura, cadeiras, dentre outros. Nesse vídeo, igualmente, eram apresentadas dicas e formas para construir um circuito. O circuito é uma atividade importante para o desenvolvimento da coordenação motora da criança, ajuda na estimulação da superação de obstáculos e auxilia a desenvolver a imaginação. A família foi responsável por complexificar o espaço para a realização dos movimentos, organizando o circuito. Foi necessário organizar o espaço previamente, separando colchões, mesas, bancos, escadinhas de madeira, caixas de papelão, cadeiras, almofadas de diversos tamanhos, bem como todos os materiais que dispunham em casa, visando ao interesse e à segurança das crianças na atividade. Após a escolha dos objetos, esses foram dispostos de formas variadas, pensando nas possibilidades de movimentação das crianças. Essa proposta pode ser realizada dentro de casa ou no pátio, zelando, constantemente, pela segurança das crianças. Abaixo, é apresentada a

Fonte: as autoras.

A primeira atividade solicitada demonstrou a importância das atividades lúdicas e recreativas durante o processo de ensino e de aprendizagem e do desenvolvimento motor de crianças. Na concepção de Bueno (1998, p. 51), os professores devem estar cientes de que “[...] a psicomotricidade faz-se necessária tanto para a prevenção e tratamento das dificuldades quanto para a exploração do potencial ativo de cada um". Essa habilidade se dá a partir de noções como coordenação, equilíbrio, lateralidade, esquema corporal e orientação espaço temporal. Assim, tais práticas psicomotoras auxiliam não somente nas questões psicomotoras, mas também nas questões voltadas à leitura, à fala, à integração e à socialização da criança. 
Figura 1 - Crianças realizando os circuitos
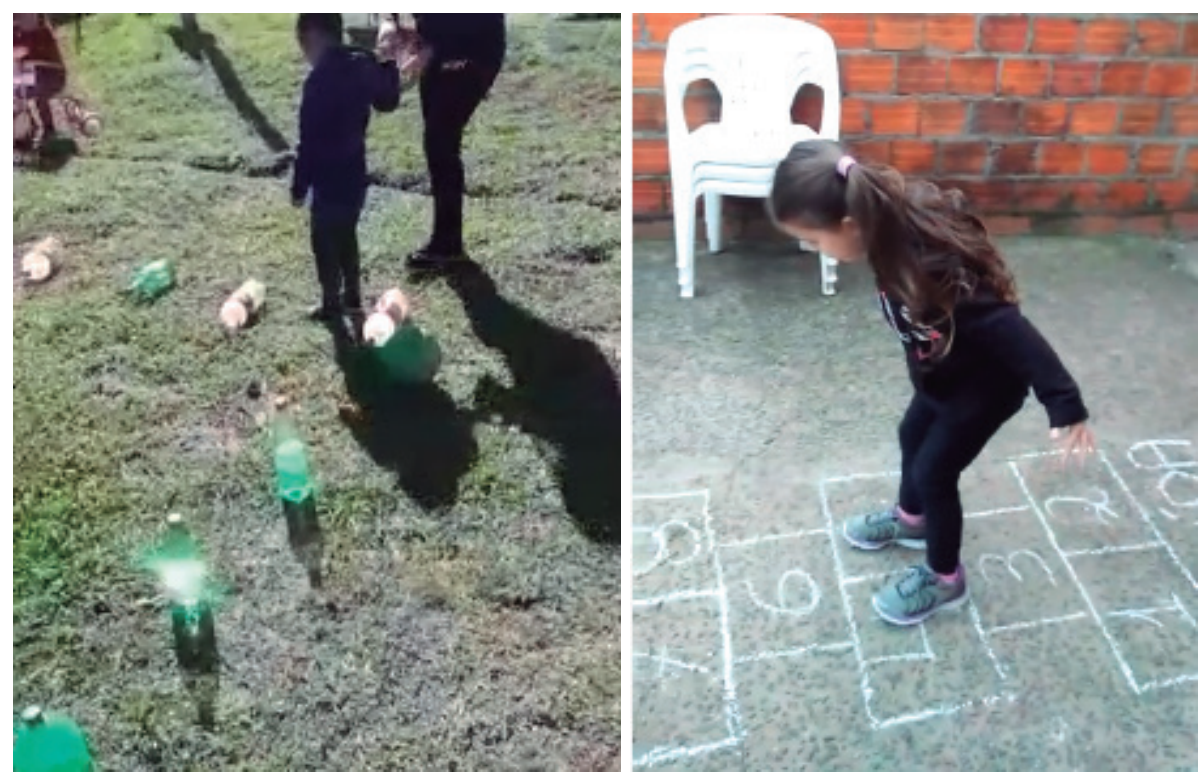

Fonte: arquivo pessoal.

A Figura 1 ilustra as crianças realizando os circuitos construídos em suas residências. Nela, é possível observar que foram explorados os espaços externos e que existe a presença do adulto como mediador da atividade. O professor, de acordo com Freire (2009, p. 6), precisar ser capaz de reconhecer e "[...] certificar-se de que seus alunos são capazes de correr, saltar, girar, rolar, trepar, lutar, lançar e pegar objetos, equilibrar-se etc.”. A necessidade de atividades psicomotoras e do entendimento de que tais atividades são expressões de um organismo integrado são apontadas também na BNCC (BRASIL, 2017) ao afirmar que na "[...] Educação Infantil, o corpo das crianças ganha centralidade, pois ele é o partícipe privilegiado das práticas pedagógicas de cuidado físico, orientadas para a emancipação e a liberdade, e não para a submissão" (p. 41).

Figura 2 - Criança realizando os circuitos

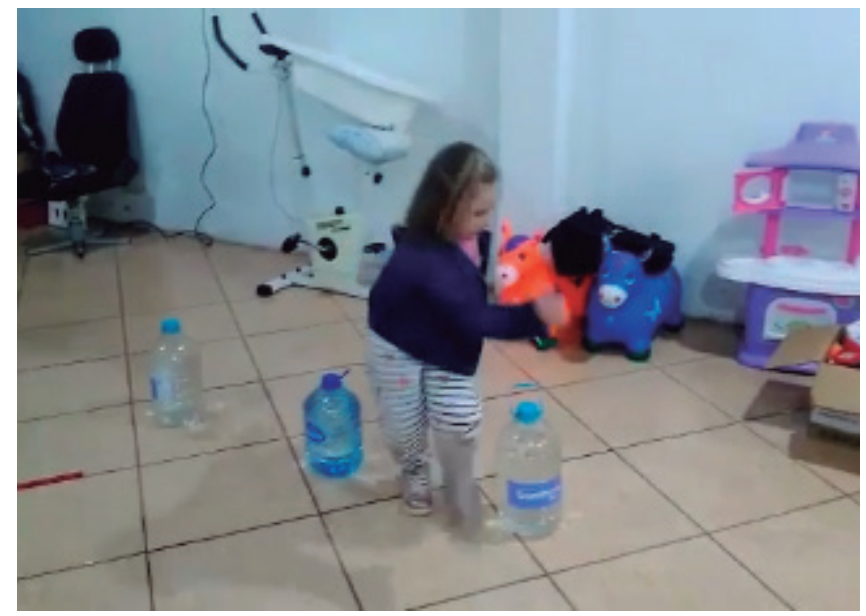

Fonte: arquivo pessoal. 
A partir dos retornos da atividade do circuito, por meio dos registros fotográficos, percebeu-se que as crianças se envolveram de forma dinâmica e lúdica, utilizando dos materiais de que dispunham em casa. Nesse sentido, entende-se que a atividade do circuito proporcionou momentos de interação interpessoal (criança-adulto), de socialização, bem como ajudou na elevação da autoestima das crianças, uma vez que proporcionou prazer e alegria sobre o sentido da atividade, além de um despertar intenso para a criatividade. Durante a atividade, demonstrou-se satisfatória a intencionalidade das famílias ao auxiliar as crianças na construção dos circuitos e na gravação dos vídeos, processo que assevera a importância da cooperação na aprendizagem durante esse período de isolamento social.

\title{
Quadro 2 - Atividade - 02 - música A mochila da Camila
}

\begin{abstract}
ATIVIDADE PROPOSTA - 02: MÚSICA A MOCHILA DA CAMILA, DO CD PANDORGA DA LUA
Inicialmente, as estagiárias gravaram um vídeo de apresentação da música $A$ mochila da Camila. Nesse, elas cantaram e chamaram as crianças para cantarem e dançarem juntos. Após, as estagiárias selecionaram e apresentaram alguns itens que apareceram na mochila.

Em um segundo momento, as acadêmicas fizeram alguns questionamentos, tais como: o que cabe na mochila? E o que não cabe na mochila das crianças?, perguntando: E aí crianças! Gostaram desta música? E vocês, há quanto tempo não usam suas mochilas? Contem para as professoras: o que cabe nas suas mochilas? Que objetos vocês gostariam de levar para a escola ou se estão brincando em casa com suas mochilas? Quais as lembranças deste momento em casa vocês gostariam de colocar na mochila? Pensem, peguem suas mochilas e vamos lá! Muita criatividade! Participem!
\end{abstract}

Em um terceiro momento, as crianças foram incentivadas a gravarem um pequeno vídeo mostrando o que cada uma colocaria na sua mochila. Sublinhou-se a importância de usarem a imaginação.

O vídeo foi postado no grupo do WhatsApp. As estagiárias sugeriram que, no caso das crianças que fossem mais tímidas, poderia ser gravado um áudio ou ser feita a representação por meio de desenho.

Desse modo, chegou-se ao seguinte roteiro para realização das atividades:

$\left.\mathbf{1}^{\circ}\right)$ Assista ao vídeo da música "A mochila da Camila".

$\mathbf{2}^{\circ}$ ) Agora, faça você um desenho com tudo que ouviu na música;

$3^{\circ}$ ) Em seguida, desenhe você com sua mochila e com tudo o que carrega dentro dela quando vai para a escola. É preciso desenhar você, a mochila e todos os objetos, ou tirar foto com você e todos os materiais da mochila.

$4^{\circ}$ ) Responda: você conhece alguém com o nome de Camila? Sim ou Não?

Quem é? Amiga da família, vizinha, colega? Diga para as professoras o que você achou dessa atividade.

$\mathbf{5}^{\circ}$ ) Registre os momentos e os encaminhe via grupo no WhatsApp (registros fotográficos ou pequenos vídeos).

Fonte: as autoras.

A segunda atividade proposta, conforme demonstra o Quadro 2, teve, como objetivo inicial, abordar a linguagem musical e a dança com os pequenos. Conforme Brescia (2003), a música acompanha o ser humano desde as primeiras civilizações. Há dados antropológicos que a indicam como fenômeno físico e psicológico que influencia diretamente o corpo humano. Segundo o autor, as experiências com música apuram os sentidos do tato, visão, olfato, permitindo que os envolvidos possam se orientar, de forma mais coesa, no espaço das atividades e, consequentemente, gerando um maior 
domínio corporal, um maior desenvolvimento muscular e um maior aumento da atividade cerebral. Dessa maneira, percebe-se a influência positiva da música para o desenvolvimento infantil, pois, de modo especial, favorece a oralidade, a organização da memória, a percepção e o desenvolvimento do pensamento em crianças pequenas, ou seja, contribui para estruturação de todos os processos mentais da criança.

A respeito da receptividade à música pelas crianças, Jeandot (1990) observa que se trata de um fenômeno que sensibiliza antes mesmo do nascimento:

\begin{abstract}
A música sensibiliza o indivíduo desde sua vida intrauterina, e este percebe os sons de seu mundo fetal como batidas cardíacas, ruídos intestinais, movimentos musculares, e os sons do ambiente que o circunda - palavras, ruídos, melodias, timbres e outros. Olhando as crianças, pode-se perceber que elas cantarolam e movimentam o corpo. Acompanhar músicas com movimentos do corpo é algo natural e imediato para a criança. A criança é um ser "rítmico-mímico", que usa espontaneamente os gestos ao sabor da sensação que eles despertam (p. 19).
\end{abstract}

A linguagem musical também é pensada como possibilidade curricular para Educação Infantil. Segundo a BNCC (BRASIL, 2017), um dos objetivos, no que tange a isso, é o de fazer com que crianças reconheçam “[...] as qualidades do som (intensidade, duração, altura e timbre), utilizando-as em suas produções sonoras e ao ouvir músicas e sons” (p. 48). Logo, a segunda atividade auxiliou a promover uma intensificação da sensibilidade, da criatividade, do senso rítmico, da imaginação, da memória, da concentração, da atenção, da autodisciplina, da socialização e da apreciação musical das crianças. A seguir, a Figura 3 ilustra alguns registros fotográficos das mochilas.

Figura 3 - crianças apresentando suas mochilas
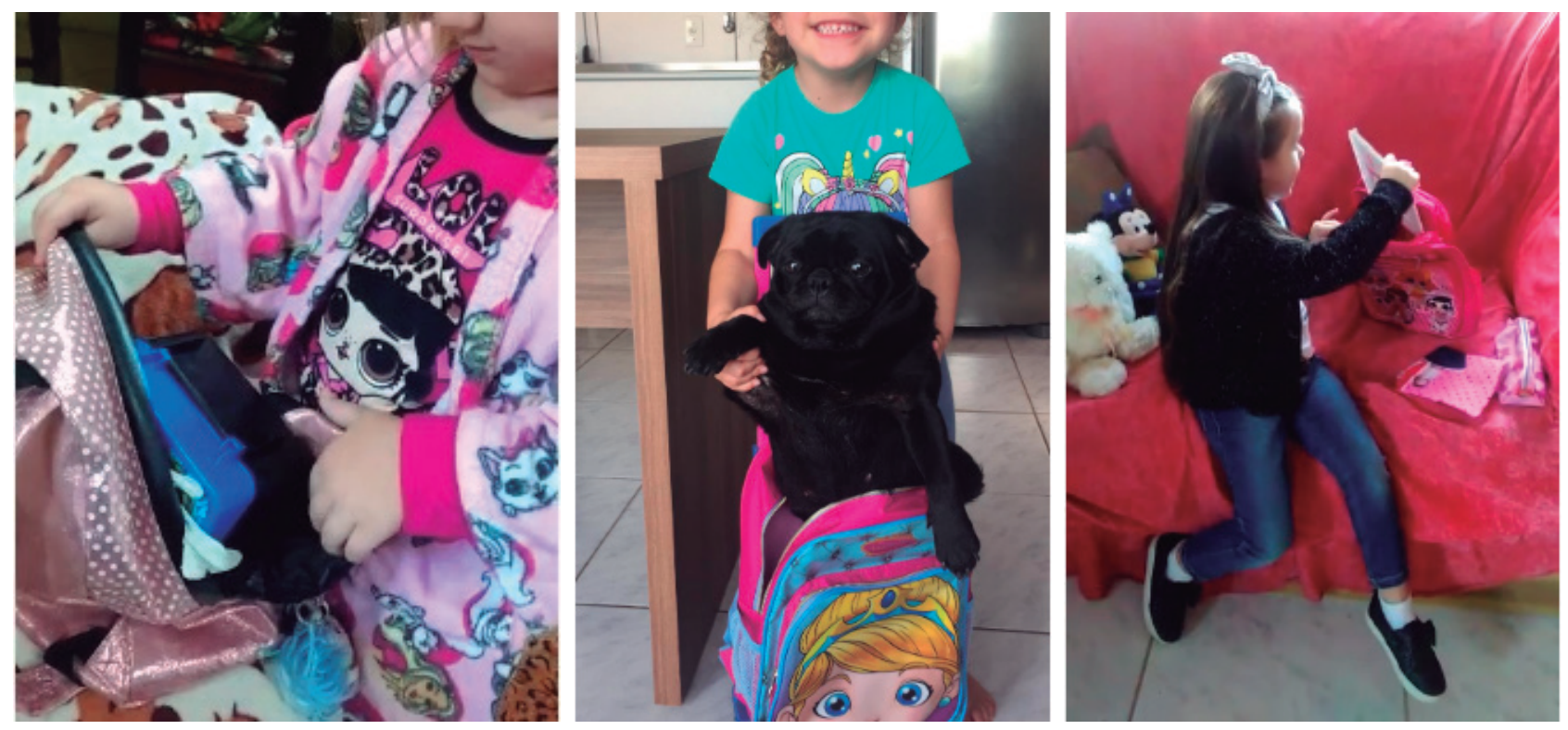

Fonte: arquivo pessoal.

Ademais, essa atividade relativa à canção, em função de se estar em um contexto de distanciamento social, sem atividades escolares presenciais, tornou-se imprescindível para lembrar as crianças da importância da relação afetiva e da organização com o material escolar. 
Quadro 3 - Atividade -03 - Contação de História

\section{ATIVIDADE PROPOSTA - 03: CONTAÇÃO DE HISTÓRIA}

Em um primeiro momento, as estagiárias gravaram um vídeo realizando uma adaptação a partir da obra Qual é a cor do amor? (2003), de autoria de Linda Strachan.

\section{Sinopse:}

O elefantinho cinzento tinha uma dúvida: qual seria a cor do amor? Curioso, perguntou para o avô, para a zebra e para todos os outros animais que encontrava pelo caminho. O dia acabou, e o elefantinho cinzento não resolveu a questão. Contudo, havia alguém para quem ele ainda não havia perguntado. Qual é a Cor do Amor? é um magnífico livro ilustrado, que apresenta as cores de maneira divertida às crianças. O verde da grama, o azul do céu, o amarelo do sol são algumas das pistas para que o elefantinho cinzento faça a sua descoberta. As ilustrações de David Wojtowycz são vibrantes. O texto de Linda Strachan encanta.

Em um segundo momento, o vídeo foi disponibilizado em grupo do WhatsApp.

Em um terceiro, solicitou-se, às crianças e a seus responsáveis, que se expressassem por meio de falas e/ou desenhos com fotos, vídeos ou áudios da atividade a partir da escuta e da visualização da história.

O amor tem cor? Sim ou não?

Qual a cor do amor para você?

Como você demonstra o amor por sua família?

A partir da atividade solicitada, solicitou-se o retorno das famílias por meio de WhatsApp.

Fonte: as autoras.

Sabe-se que a contação de história, foco da terceira atividade, desde há muito está presente nas atividades pedagógicas com vistas a dar sentido e significado ao processo de aprendizagem na Educação Infantil. Além de estimular a construção do conhecimento das crianças e de estimular a imaginação, a contação de histórias incentiva a criatividade e possibilita, a partir dela, diversas outras formas de expressão e de interação. A respeito da importância dessas iniciativas, pode-se recorrer ao pensamento de Abramovich (1995):

Ler histórias para crianças, sempre, sempre... É poder sorrir, rir, gargalhar com as situações vividas pelas personagens, com a idéia do conto ou com o jeito de escrever dum autor e, então, poder ser um pouco cúmplice desse momento de humor, de brincadeira, de divertimento... É também suscitar o imaginário, é ter a curiosidade respondida em relação a tantas perguntas, é encontrar outras idéias para solucionar questões (como as personagens fizeram...). É uma possibilidade de descobrir o mundo imenso dos conflitos, dos impasses, das soluções que todos vivemos e atravessamos - dum jeito ou de outro - através dos problemas que vão sendo defrontados, enfrentados (ou não), resolvidos (ou não) pelas personagens de cada história (cada uma a seu modo)... É a cada vez ir se identificando com outra personagem (cada qual no momento que corresponde àquele que está sendo vivido pela criança)... e, assim, esclarecer melhor as próprias dificuldades ou encontrar um caminho para a resolução delas... (p. 17).

Dessa forma, a leitura surge como um empreendimento de fruição, que resulta em ganhos significativos no processo ensino e de aprendizagem. A partir do prazer evocado pelo enredo e pelas personagens das histórias, a leitura dirige as crianças a um letramento mais complexo, capaz de 
permitir que possam, gradualmente, realizar relações intertextuais com outros textos ficcionais, com acontecimentos sociais ou com fatos da sua experiência individual.

Figura 4 - Crianças produzindo a partir da contação de história
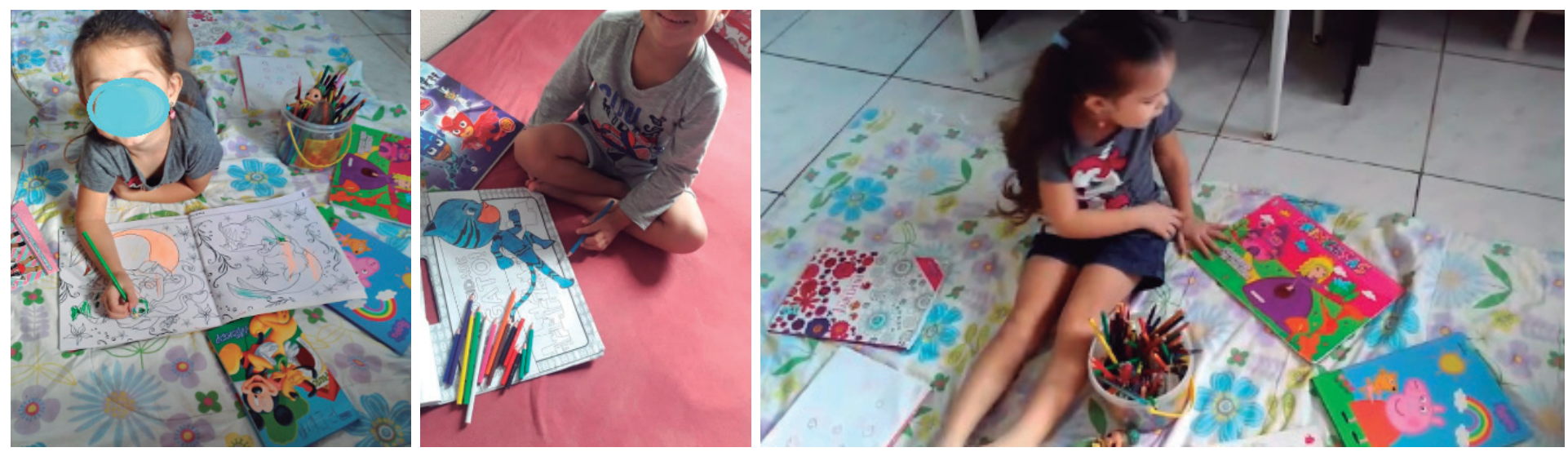

Fonte: arquivo pessoal.

A terceira atividade desenvolvida, como ilustra a Figura 4, demonstrou que a contação de histórias, além de fazer a criança interagir com textos que circulam no contexto familiar, comunitário e escolar, pode proporcionar, por meio do imaginário, a construção e a pintura de desenhos. De acordo com a BNCC (BRASIL, 2017), é a partir dessa interação com textos que a criança vai adquirindo sua concepção de língua escrita, reconhecendo diferentes usos sociais dessa habilidade:

\footnotetext{
Na Educação Infantil, a imersão na cultura escrita deve partir do que as crianças conhecem e das curiosidades que deixam transparecer. As experiências com a literatura infantil, propostas pelo educador, mediador entre os textos e as crianças, contribuem para o desenvolvimento do gosto pela leitura, do estímulo à imaginação e da ampliação do conhecimento de mundo (BRASIL, 2017, p. 42).
}

Desse modo, a contação de histórias se configura como uma alternativa pedagógica para o estímulo à leitura, uma vez que, além de desenvolver a fala e de intensificar o vocabulário, promove, progressivamente, uma melhor na escrita. Além disso, nesse contexto de distanciamento social, pode-se reiterar mais enfaticamente que o discurso da leitura não deve restringir-se ao contato com livros. Em uma acepção ampla de leitura, filmes e séries educativas podem contribuir, progressivamente, seja para o entretenimento ou para a educação das crianças nesse contexto de pandemia e de ensino remoto.

\section{CONSIDERAÇÕES FINAIS}

O Estágio Curricular Supervisionado, na Educação Infantil, com a turma de Pré A, na modalidade de ensino remoto, revelou-se desafiador em meio à pandemia da COVID-19, tanto para as estagiárias quanto para professora regente. Os desafios foram no sentido de como propor e de que maneira implementar atividades pedagógicas que mantivessem o vínculo com as crianças e com as 
famílias/responsáveis mesmo diante das limitações da grande maioria delas no referente ao acesso à internet, a computadores e a celulares, ferramentas essenciais para realização das atividades.

Ainda sobre as dificuldades no que tange ao uso de ferramentas eletrônicas e digitais, o acesso das crianças às atividades dependia da conexão de internet, pois grande maioria possuía dados móveis $^{5}$, frequentemente instáveis. É importante esclarecer que, das 27 crianças que compõem a turma, em média, 07 crianças retornaram cada uma das atividades. Julga-se que o número pequeno de retornos se justifique em função de que a proposta de estágio, na modalidade remota, foi a primeira iniciativa que as crianças e familiares/responsáveis experenciaram, uma vez que a suspensão das aulas se deu em no final do mês de março, e o estágio iniciou em maio. Entende-se que, possivelmente, houve pouco tempo para reorganização das famílias nesse novo contexto de aprendizagem. Ademais, para muitas crianças, foi a primeira experiência escolar. É preciso lembrar que o ano letivo de 2020 iniciou no final do mês de fevereiro e houve a suspensão dele algumas semanas depois. Assim, o tempo foi insuficiente para as crianças vivenciarem e compreenderem a organização da escola e a rotina na educação infantil.

A rotina, na Educação Infantil, torna-se um fator de segurança, pois a criança consegue se orientar em relação ao tempo-espaço, favorecendo a previsão de situações que possam vir acontecer. Nesse contexto, ela se sente mais segura e confiante, desenvolvendo sua autonomia. Nessa direção, considera-se a rotina uma forma de assegurar a tranquilidade do ambiente, tanto da sala de aula quanto escolar, uma vez que a repetição das ações cotidianas sinaliza às crianças cada situação do dia. Isso significa afirmar que a repetição de determinadas práticas pedagógicas dá estabilidade e segurança às crianças e às professoras.

Destaca-se, no entanto, que as dificuldades enfrentadas não fizeram que as crianças não se dedicassem à realização das atividades, já que as que participaram sempre interagiram com criatividade e entusiasmo. Em vista disso, a experiência formativa evidenciou que essa criatividade e entusiasmo das crianças deve-se muito à necessidade de socialização da qual carecem durante esse período de distanciamento. Portanto, as atividades solicitadas puderam aferir que as práticas pedagógicas, durante períodos de isolamento social, precisam priorizar o afloramento da afetividade e da imaginação das crianças, a fim de preservar a saúde mental de cada uma e de fortalecer os vínculos com a escola e com a professora.

A experiência demonstrou desafios impostos aos profissionais da educação, dentre eles às (aos) pedagogas(os), nesse contexto de pandemia, de modo especial às professoras de Educação Infantil, uma vez que o contato, por meio virtual, com as crianças, é inédito em contexto brasileiro. Contudo, essa experiência, ainda que em meio a uma pandemia, abre a discussão acerca de uma proximidade também virtual futuramente, paralela aos encontros presenciais nas instituições de Educação Infantil.

\footnotetext{
${ }^{5}$ Dados móveis trata-se da internet do seu celular, pacotes de dados contratados pelas operadoras de telefônicas para uso da internet e aplicativos.
} 
Isso poderá se dar com orientações institucionais e familiares sobre o uso oportuno das redes digitais com finalidades educacionais e socioculturais. Acredita-se que encontros com as crianças, pela rede, podem ser, além de uma oportunidade de socialização, uma forma de se expressarem e de aprenderem.

Por fim, a proposição de estágio curricular, na Educação Infantil, na modalidade remota, configurou-se como uma experiência formativa em que as estagiárias mobilizaram a produção de conhecimentos e de aprendizagens necessárias à docência, em uma perspectiva reflexiva dos enfrentamentos do como ensinar e de que modo aprender em tempos de pandemia. Paralelamente a isso, a experiência também demonstrou a necessidade de um prisma sensível para com a realidade social das crianças e das famílias, além de uma percepção mais aguda acerca de problemas de ordem psíquica que podem interferir no cotidiano das crianças nesse momento de distanciamento social.

\section{REFERÊNCIAS}

ABRAMOVICH, F. Literatura infantil: gostosuras e bobices. 5. ed. São Paulo: Scipione, 1995.

BADIOU, A. Sobre a situação epidêmica. In: DAVIS, Mike. et al. DAVIS, M. et al. Coronavírus e a luta de classes. Terra sem Amos: Brasil, 2020.

BRASIL. Base Nacional Comum Curricular. Brasília: MEC, 2017. Disponível em: https://bit.ly/3r54wyO. Acesso em: 25 jun. de 2020.

BRASIL. Portaria n⿳ 343, de 17 de março de 2020. Dispõe sobre a substituição das aulas presenciais por aulas em meios digitais enquanto durar a situação de pandemia do Novo Coronavírus - COVID-19. Brasília, MEC, 17. mar. 2020. Disponível em: https://bit.ly/2LIK0UH. Acesso: 05 ago. 2020.

BRÉSCIA, V, L. P. Educação Musical: bases psicológicas e ação preventiva. São Paulo: Átomo, 2003.

BUENO, J. M. Psicomotricidade: teoria e prática. São Paulo: Lovise, 1998.

GORDON, R. O futuro pode ser feminino, mas a pandemia é patriarcal. In: ROQUETA, M. et al. Coronavírus, gênero e a luta de classes. Terra sem Amos: Brasil, 2020.

JEANDOT, N. Explorando o Universo da Música. São Paulo: Scipione, 1990. 
MARQUEZAN, F. F.; FLEIG, M. T. Diários investigativos no contexto da orientação e supervisão do estágio curricular. In: FREITAS, D. S.; GIORDANI, E. M.; CORRÊA, G. C. (Orgs.). Ações Educativas e Estágios Curriculares Supervisionados. Santa Maria: Ed. da UFSM, 2007.

MINAYO, M. C. S. Pesquisa social: teoria, método e criatividade. 33. ed. Petrópolis, RJ: Vozes, 2013.

NÓVOA, A.; FINGER, M. (Org.). O método (auto)biográfico e a formação. Natal, RN: EDUFRN; São Paulo: Paulus, 2010.

ORGANIZAÇÃO MUNDIAL DA SAÚDE. Folha informativa - COVID-19 (doença causada pelo novo coronavírus). Organização Pan-Americana de Saúde; Organização Mundial de Saúde, 2020. Disponível em: https://www.paho.org/bra. Acesso em: 05 ago 2020.

PINHEIRO, C. Como fica a educação das crianças pequenas em tempos de coronavírus? Disponível em: https://bit.ly/3p06NtE. Acesso em: 26 jun2020.

SANTA MARIA. Decreto Executivo N 53, de 16 de março de 2020. Dispõe sobre medidas temporárias de prevenção do COVID-19 (novo coronavírus) e dá outras providências. Prefeitura Municipal de Santa Maria: Casa Civil, 16. mar. 2020. Disponível em: https://bit.ly/34kZtkl. Acesso: 05 de agosto de 2020.

RIO GRANDE DO SUL. Decreto $\mathbf{n}^{0} \mathbf{5 5 . 1 5 4}$, de $\mathbf{1}^{\circ}$ de abril de 2020. Reitera a declaração de estado de calamidade pública em todo o território do Estado do Rio Grande do Sul para fins de prevenção e de enfrentamento à epidemia causada pelo COVID-19 (novo Coronavírus), e dá outras providências. Governo do Estado do Rio grande do Sul. Porto Alegre: Palácio Piratini, 1. abr. 2020. Disponível em: https://bit.ly/3r2odHL. Acesso em: 05 ago. 2020.

SANTOS, J. M. O.; ESTEVAM, R. A.; MARTINS, T. M. Pesquisa (auto)biográfica. Ensaios pedagógicos, Sorocaba, v. 2, n. 1, p. 45-53, 2018. Disponível em: https://bit.ly/3oXupz0. Acesso em: 05 ago. 2020. 